\title{
EM BUSCA DO NADA: CONSIDERAÇÕES SOBRE OS ARGUMENTOS A FAVOR DO VÁCUO OU DO ÉTER
}

Roberto de Andrade MARTINS ${ }^{1}$

- RESUMO: Este artigo discute a possibilidade do vácuo absoluto - ou seja, de um espaço no qual não exista qualquer substância. A motivação desse estudo é o contraste entre a quase unanimidade dos filósofos, até Descartes, contra a possibilidade do vácuo - e a mudança ocorrida no século XVII, quando, a partir de estudos experimentais de Torricelli e Pascal, passou-se a aceitar a possibilidade e existência efetiva do vácuo. Contrariando a opinião atual mais comum, este artigo procura mostrar que uma concepção hoje em descrédito na ciência - a de um éter - é preferivel à concepção de um vácuo, por vários motivos. Em primeiro lugar, porque não se pode mostrar, empiricamente, que o éter não existe; em segundo lugar, porque um vácuo é impensável; em terceiro, porque a concepção de um éter é útil à compreensão dos fenômenos físicos; e, em quarto lugar, porque a hipótese da existência de um éter em espaços aparentemente vazios é útil ao progresso futuro da ciência. O artigo procura mostrar também que nenhum avanço recente da ciência alterou essas antigas conclusões e que nenhum avanço futuro pode alterá-las.

- UNITERMOS: Espaço; vácuo; éter; conhecimento a priori; observáveis; epistemologia.

\section{1. Éter ou vácuo: razão ou experiência}

Durante muitos séculos, a maior parte dos pensadores negou a possibilidade de um vácuo. Afirmava-se que todo espaço aparentemente vazio (como os espaços celestes) estava totalmente preenchido por alguma substância imperceptível - o éter. Aristóteles negou o vácuo; toda a escolástica negou o vácuo; Descartes também o negou. Atualmente, pelo contrário, a grande maioria dos cientistas (físicos, químicos, astrônomos) admite que quase tudo é vácuo: os espaços intra-atômicos são vazios; os espaços interestelares são praticamente vazios (com uma partícula por quilômetro cúbico); e é possível produzir, artificialmente, espaços evacuados no laboratório. Como os filósofos confiam nos cientistas, também passaram a acreditar na possibilidade do vácuo e na inexistência do éter. Terá a ciência mostrado que os filósofos se enganaram redondamente, ao negarem a possibilidade do vácuo? Quem conhece um pouco de

1. Grupo de História e Teoria da Ciência - DRCC - IFGW - UNICAMP - 13081 - Campinas - SP 
história da ciência sabe que a aceitação do vácuo se deu em duas etapas principais. No século XVII, os experimentos de Torricelli, Pascal, Boyle e outros mostraram que a Natureza não tem "horror ao vácuo", como se acreditava: era aparentemente possível produzir vácuos artificiais, através de barômetros, seringas, bombas de vácuo etc. (Martins, 1989). No entanto, após um período (no século XVIII) no qual a aceitação do vácuo foi generalizada, o éter foi reintroduzido através dos estudos ópticos e eletromagnéticos, no século XIX². Apenas com a aceitação da teoria da relatividade, no início do século XX, o éter luminífero e eletromagnético foi também abandonado. Mas o abandono do éter e a aceitação do vácuo, em cada uma dessas etapas, pode ter sido bem justificados ou não. O consenso ou a preferência dos cientistas por uma idéia não significa que ela foi bem fundamentada.

Na verdade, até hoje, há físicos que rejeitam a teoria da relatividade e defendem a existência de um éter ${ }^{3}$. Mas estes são geralmente vistos pelos cientistas "normais" como excêntricos e, às vezes, tratados como párias pelos seus colegas. São considerados como pertencentes ao mesmo grupo dos que defendem a teoria da Terra oca e outros absurdos semelhantes ${ }^{4}$.

Este artigo apresentará os argumentos fundamentais em que, através dos séculos, se fundamentaram os defensores e os adversários do vácuo; uma análise filosófica, discutindo os limites de nossa possibilidade de conhecer, defenderá a posição (que sei ser hoje muito impopular) de que a razão se opõe aos defensores do vácuo e que os argumentos básicos que mostram isso já estavam claros muitos séculos atrás.

Este artigo é uma homenagem a Descartes. Não se trata de um trabalho histórico e seu tema não é a obra de Descartes. No entanto, o ponto de vista aqui adotado é claramente favorável, no caso específico que estuda, a uma posição que pode ser denominada 'racionalista': não é preciso ir ao laboratório para se determinar se o vácuo existe ou não; nossa razão pode mostrar que o vácuo é impossível. Isso não quer dizer que a observação e a experimentação sejam sempre dispensáveis; mas quer dizer que um empirismo cego é pura perda de tempo, em certas questões fundamentais. Pascal fez muitos experimentos e defendeu a existência do vácuo. Descartes, sem se dedicar a experimentos semelhantes, mas aceitando os experimentos alheios como corretos, negou o vácuo e afirmou o éter. Por sua conclusão e pelo seu método "científico", Pascal atrai imediatamente a simpatia de um pesquisador moderno, que é tentado a dizer: "Coitado desse Descartes, só disse bobagens!" Não vamos negar o valor do trabalho de Pascal; mas vamos procurar mostrar o "outro lado". Isso permitirá, esperamos, uma melhor compreensão do papel da razão na ciência.

\section{O argumento empírico}

Será possível mostrar-se, empiricamente, a existência do vácuo? Esta é a primeira questão a ser discutida aqui. Para poder discuti-la, é necessário, em primeiro 
lugar, esclarecer o que significa "vácuo". Uma garrafa vazia não apresenta um vácuo. Por quê ? Porque ela está vazia de líquido, mas cheia de ar. Um vácuo é um espaço totalmente vazio, no qual não existe nenhum ente. Para enfatizar esse significado, pode-se também falar em "vácuo absoluto", que pode ser contrastado com um "vácuo relativo" - um espaço no qual não existem alguns tipos de entes.

Pode-se imaginar que, no século XVII, Torricelli, Pascal e outros mostraram a existência do vácuo empiricamente, mostrando a existência de um espaço totalmente vazio, produzido no topo dos barômetros. A questão básica, no entanto, é se esse era um vácuo absoluto ou relativo.

É necessário, inicialmente, esclarecer um ponto básico: um físico não pode mostrar, em seu laboratório, diretamente, que o vácuo existe. Ao produzir um espaço vazio (com uma bomba de vácuo ou qualquer outro dispositivo), é possível exibir um lugar onde não há sólidos, líquidos ou gases perceptíveis ${ }^{5}$, ou seja, um vácuo relativo; mas a questão central não é essa. Descartes admitia que, no vazio produzido em um barômetro, não havia matéria sensível. Mas admitia que existia o éter ou matéria sutil. Ou seja: mostrar que em certo local não existem certos tipos de substâncias conhecidas não prova que não existe nenhuma substância.

A impossibilidade da experiência do vazio absoluto é colocada claramente por Kant, por exemplo:

\begin{abstract}
Podemos terminar pela questão bem conhecida: deve-se admitir espaços vazios no mundo? Não se pode contestar sua possibilidade; pois todas as forças da matéria exigem o espaço e como esse espaço comporta as condições de propagação dessas forças, ele necessariamente antecede toda matéria. Assim, atribui-se à matéria uma força de atração na medida em que ela ocupa um espaço em torno dela, pela atração, sem no entanto preenchê-lo; esse espaço pode portanto ser concebido como vazio mesmo onde a matéria age; pois ela não atua aí por forças repulsivas e portanto não o preenche. No entanto, nenhuma experiência, nenhuma conclusão a partir dela, nenhuma hipótese necessária nos autorizam a admitir espaços vazios como reais. Toda experiência, de fato, apenas nos faz conhecer espaços relativamente vazios e pode-se explicá-los perfeitamente, qualquer que seja seu grau, pela propriedade que a matéria tem de preencher seu espaço por uma força de expansão que aumenta ou diminui sempre ao infinito e não se tem nenhuma necessidade de espaços vazios (Kant, 1971, p.116-7) ${ }^{6}$.
\end{abstract}

É interessante notar que Kant afirma isso no fim do século XVIII - em uma época em que se falava com grande liberdade acerca do vácuo e não se via nenhum problema nisso.

A argumentação para afirmar a existência do vácuo tem, portanto, dois lados. Um deles corresponde aos conhecimentos empíricos estabelecidos no século XVII e que podem ser colocados sob a seguinte forma: é possível produzir espaços vazios macroscópicos nos quais não existem as substâncias materiais perceptíveis conhecidas. Porém, mesmo admitindo-se isso, resta o segundo e mais difícil passo: excluir, a partir daí, a existência de uma substância imperceptível (o éter) nesses espaços aparentemente vazios e poder então afirmar que eles são absolutamente vazios (ou seja: o vácuo absoluto). 
Pascal ingenuamente acreditava que os "antigos" apenas acreditavam na impossibilidade do vácuo por não possuírem os conhecimentos empíricos dos modernos. Chega a sugerir que, se Aristóteles vivesse em sua época, aceitaria a existência do vácuo. Mas o conhecimento empírico apenas pode mostrar um vazio relativo ou aparente. Como passar daí ao vazio absoluto?

Pascal argumentava a favor do vácuo de uma forma que pode ser assim esquematizada:

A1 - Existem espaços aparentemente vazios (nos quais não se observa a existência de sólidos, líquidos ou gases).

A2 - Esses espaços vazios são totalmente vazios de qualquer substância observável (não só substâncias já conhecidas, mas de qualquer substância, mesmo desconhecida, perceptível).

Portanto,

V1 - Esses espaços são absolutamente vazios; ou seja: existe o vácuo.

A primeira premissa é a única que é diretamente estabelecida pela experiência. A segunda (A2) é uma generalização empírica que pode ser submetida a testes, embora não possa ser provada por nenhum conjunto finito de experimentos. Pascal desafiava aqueles que negavam o vácuo a mostrar que havia algo no espaço aparentemente vazio e dizia que, enquanto não lhe mostrassem nada, ele tinha o direito de admitir que o espaço estava absolutamente vazio. Há, no entanto, uma lacuna nesse raciocínio. A conclusão não sai imediatamente das premissas. É necessário, além de A1 e A2, admitir também que onde não há nada observável não há nada no sentido absoluto. Ou seja: o raciocínio deve ser completado assim:

A1 - Existem espaços aparentemente vazios (nos quais não se observa a existência de sólidos, líquidos ou gases).

A2 - Esses espaços vazios são totalmente vazios de qualquer substância observável (não só substâncias já conhecidas, mas de qualquer substância, mesmo desconhecida, perceptível).

A3 - Não existem substâncias inobserváveis.

Portanto,

V1 - Esses espaços são absolutamente vazios; ou seja: existe o vácuo.

Esse argumento é rigoroso no sentido de que, se as premissas A1, A2 e A3 são aceitas, a conclusão V1 deve ser também necessariamente aceita. No entanto, pode-se fugir a essa conclusão negando pelo menos uma das premissas.

O ponto crucial é a premissa A3. Vamos nos deter nela, ou, mais exatamente, na sua aplicação ao caso do éter.

Se uma coisa é inobservável, não se pode mostrar que ela está em um local. Mas, pelo mesmo motivo, não se pode mostrar que ela não está em um local: ela escapa à observação. Por isso, a premissa A3 não pode ser uma conclusão fundamen- 
tada na observação - assim como não se pode, por observação, afirmar ou negar a presença de um anjo em um local. Como, então, se poderia fundamentar a proposição A3?

As alternativas são: ou a premissa A3 não tem fundamento ou tem um fundamento não empírico. Não há outra alternativa: afirmar que $\mathrm{A} 3$ tem fundamento empírico é um erro. Pela sua forma, a premissa A3 é metafísica e ontológica. Ela só poderia ser fundamentada a partir de outros pressupostos metafísicos e, hoje em dia, seria difícil querer fundamentar a ciência pela metafísica.

É difícil ver como A3 poderia ser fundamentada. Mas, se ela não pode ser fundamentada, não se pode rejeitar a existência de "algo" no espaço aparentemente vazio e, portanto, pode-se aceitar a existência de um éter ou matéria sutil. Se nenhum outro argumento for adicionado, a aceitação ou negação do éter seria, então, uma questão de mera preferência pessoal.

Mas pode-se substituir A3 por uma versão mais atenuada. Ao invés de afirmar que aquilo que é inobservável não existe, pode-se afirmar que aquilo que é inobservável não pode ser objeto de estudo pela ciência. Assim, o efeito final seria o mesmo: eliminar o éter da ciência. Mas o argumento, ao invés de ser ontológico, torna-se epistemológico. Pode-se, igualmente, invocar o velho princípio de que não se deve multiplicar os entes sem necessidade. Esta é uma regra metodológica. Indica como o ser humano deve proceder e não como a natureza é.

Vamos esquematizar o argumento contra o éter, sob esta nova forma, baseado em sua inobservabilidade:

B1 - O éter suposto pelos que afirmam sua existência não é observável, ou seja: é invisível, impalpável; não afeta os instrumentos de medida nem os sentidos.

B2 - Aquilo que é inobservável não pode ter sua existência testada: não se pode estabelecer um critério empírico para testar se essa coisa está presente ou não em certo local.

B3 - Aquilo que não é testável não é objeto de discussão científica e deve, por isso, ser excluído da ciência.

Portanto,

V2 - O éter deve ser excluído da ciência.

Tal tipo de argumento foi utilizado por Einstein e outros (Martins, 1981). O argumento, de tipo positivista7, é semelhante ao utilizado por Ernst Mach para negar o espaço absoluto de Newton, e ao utilizado por Ostwald para negar os átomos na química, em fins do século XIX. O argumento, conforme esquematizado acima, utiliza: uma premissa sobre o éter (B1) que é admitida pelos próprios defensores do éter; uma análise do conceito de testabilidade (B2) e um critério epistemológico (B3) que demarca conceitos científicos de conceitos não científicos, semelhante ao operacionalismo de Bridgman. A premissa A3 do argumento anterior, atenuada e transformada 
como foi indicado acima, deve ser compreendida como equivalente a B2+B3; ou seja: deveríamos substituí-la por:

A3' - Substâncias inobserváveis são cientificamente inaceitáveis. e a conclusão deve ser reformulada assim:

V1' - Cientificamente, esses espaços devem ser considerados absolutamente vazios; ou seja: cientificamente, o vácuo existe.

Ou seja: de acordo com essa posição, não se pode afirmar que o vácuo existe e sim que essa é a conclusão científica, dentro de uma certa concepção de ciência (positivista); fora dessa concepção (por exemplo, em uma discussão metafísica), não se poderia negar a existência de substâncias inobserváveis.

Esta reformulação do argumento e da conclusão pode parecer suficientemente forte. Afinal, não estamos aqui interessados em metafísica e sim em ciência: queremos saber se os cientistas estão bem justificados em negar o éter e em afirmar o vácuo.

No entanto, é importante notar que a conclusão depende, agora, de modo crucial, de uma determinada concepção de ciência; e existem diferentes concepções de ciência - sendo o positivismo apenas uma delas. Para todos os filósofos que estão a par dos desenvolvimentos recentes da filosofia da ciência, poderá parecer desnecessário enfatizar este ponto. Ocorre, no entanto, que entre os cientistas a tradição positivista ainda está firmemente enraizada por não aparecer nenhuma alternativa consensualmente aceita. A maior parte dos físicos ainda imagina que o operacionalismo é uma concepção válida sobre conceitos e medidas em física. Vale a pena, portanto, chamar a atenção para este ponto: no argumento analisado acima, é essencial a aceitação de uma concepção epistemológica; e esta concepção é inadmissível, sob o ponto de vista filosófico.

Infelizmente, discutir esse aspecto nos levaria longe demais. Ele envolve toda a concepção sobre o que é ou o que não é científico, e extrapola o modesto tema deste artigo.

Embora o positivismo tenha sido abandonado e enterrado, isso não significa que todas as suas idéias estão necessariamente erradas. É preciso, portanto, discutir em detalhe que tipo de fundamentação poderia ser dada a essas premissas, em particular, para verificar se podem ser realmente rejeitadas.

\section{Os inobserváveis e a ciência}

Vamos retornar à discussão do vácuo e do éter, analisando no contexto dessa discussão apenas alguns aspectos epistemológicos. Reformulemos a argumentação contra o éter da seguinte forma: "Tudo aquilo que é inobservável é inútil, sob o ponto de vista científico; seria perda de tempo tentar incluir essas coisas na ciência, pois 
não servem para nada." Cabe-nos discutir com um pouco mais de detalhe as noções de "observável" e de "utilidade científica".

Há diferentes tipos de inobserváveis ${ }^{8}$. O conceito mais elementar de inobservável ("inobservável sensorial") é o de algo que não pode ser captado pelos sentidos. O ar é um inobservável visual. O interior de um corpo opaco é inobservável sensorialmente (a menos que ele seja quebrado ou aberto). O lado oculto da Lua é inobservável para quem esteja na Terra. Um núcleo de uma célula epitelial é inobservável a olho nu. Um elétron é inobservável sensorialmente. As ondas de rádio e os raios X são inobserváveis sensorialmente.

Ora, todos esses são exemplos de coisas inobserváveis que ninguém considera cientificamente absurdas. Devem existir, portanto, diferentes classes de inobserváveis, se alguns são admissíveis e outros proibidos (ou inúteis) na ciência. Ou seja: se o éter fosse inadmissível na ciência meramente por ser inobservável, isso significaria que basta ser inobservável para ser inadmissível na ciência - e todos os inobserváveis acima relacionados seriam igualmente inadmissíveis. Os contra-exemplos indicam ou que a atitude geral é incoerente (e que eles também deveriam ser banidos) ou que não basta ser inobservável para ser banido da ciência. Apenas alguns inobserváveis (um tipo ou espécie) deveriam ser eliminados da ciência.

Para contraste, examinemos um caso extremo. Imaginemos a existência de um mundo "paralelo" ao nosso, contendo matéria, seres vivos etc., porém sem qualquer possibilidade de comunicação conosco, por estar "em outra dimensão". Suponhamos que essa impossibilidade de interação entre os seres dos dois mundos seja intransponível. Nesse caso, para nós, o outro mundo é inobservável em princípio: jamais poderemos ter informações empíricas direta ou indiretamente ligadas à sua existência; se ele deixasse de existir ou sofresse qualquer alteração, não poderíamos sabê-lo, pois essas mudanças não afetariam nosso mundo. Nesse caso extremo, é difícil imaginar que algum cientista se dedique seriamente a discutir como seria esse mundo e discutir sua existência. Este exemplo, aliás, é famoso: foi utilizado por Heisemberg (1956) para justificar o princípio de incerteza, em uma de suas obras.

Este caso pertence a um tipo especial de inobserváveis: aqueles que não estão conectados causalmente (por relações de causa e efeito) ao nosso mundo observável. Há inobserváveis que, embora escapem às nossas sensações, produzem efeitos observáveis e são, por isso, parte de nosso mundo físico - como os raios X. Isto é: podemos caracterizar nosso mundo físico não só como aquilo que percebemos sensorialmente mas também contendo entes que não percebemos, mas que atuam sobre outros que percebemos, direta ou indiretamente. Se excluirmos do mundo físico certos entes inobserváveis, haverá fenômenos inexplicáveis, pois não terão causa pertencente ao mundo físico. A prática científica usual admite esse tipo de inobservável, na construção daquilo que podemos denominar "modelos científicos substanciais" - teorias capazes de explicar regularidades observáveis com o uso de entes inobserváveis. A utilidade científica desses entes não está em sua relação direta com nosso domínio sensorial, mas na explicação desse mundo sensível. Um inobservável 
que, por princípio, não tem conexão causal, direta ou indireta, com o nosso mundo sensível, não tem utilidade em modelos substanciais, já que não pode explicar fatos do mundo sensível.

A partir desta análise, vê-se que, sob o ponto de vista de compreensão do mundo sensível, é útil a introdução de certos tipos de inobserváveis. Eles só são inúteis se não possuem papel causal no mundo sensível.

Essa posição aqui descrita é parte da prática científica; no entanto, é atacada por filósofos que desejariam eliminar da ciência, ao máximo, todo elemento arbitrário. Não se pode assegurar, a partir da observação de certos fenômenos, qual a sua causa inobservável: sempre são possíveis vários modelos substanciais conflitantes, capazes de dar conta dos mesmos fenômenos. Essa arbitrariedade dos modelos foi o que motivou Ernst Mach e Pierre Duhem a negar o papel explicativo dos modelos substanciais e a abandoná-los em favor de uma ciência fenomenológica, que não procure ir além dos fenômenos observáveis e de suas regularidades. Mas podemos realmente desistir do uso desse tipo de modelos?

Pensem em um espetáculo de mágica, em que um prestidigitador faça aparecer "do ar" uma série de cigarros acesos. Nossos sentidos não nos mostram a origem desses cigarros; imaginamos, então, mecanismos ocultos pelos quais eles poderiam ter surgido. Pelo que podemos observar, no entanto, enquanto espectadores, não é possível saber qual de várias explicações é a correta: os cigarros estavam escondidos na manga do casaco? caem do alto do palco? ou saem de outro lugar? Não sabemos qual a explicação correta. No entanto, uma coisa é certa: o conhecimento de que os cigarros surgem, sem o conhecimento de sua origem, é incompleto e insatisfatório e somos, naturalmente, levados a pensar em explicações envolvendo coisas que não observamos. Não parece possível desistir de explicações desse tipo.

Embora, na ciência, não possamos chegar à certeza sobre o modelo substancial mais adequado à explicação de certos fatos, não há motivo para proibir esses modelos. Eles só são prejudiciais, na ciência, quando confundidos com a realidade. Esta, aliás, é uma posição defendida por Henri Poincaré - que aceitava o éter.

Em cada domínio de estudos, pode ser útil ou não introduzir modelos substanciais. Se os entes observáveis não explicam tudo o que se observa (isto é: se o mundo observável não é causalmente fechado ou auto-suficiente), é útil introduzir entes inobserváveis: estes poderão aumentar nossa compreensão do mundo observável.

Esta posição epistemológica, que estamos defendendo, não é a única possível. A ciência pode ser pensada de diferentes formas. Parece-nos, no entanto, que a prática científica, durante milênios, fez uso de modelos substanciais, e é difícil acreditar que essa prática cessará. Desde que essa prática não seja incoerente e não colida com outros aspectos da ciência, sua defesa é filosoficamente aceitável. Não vejo motivos para que essa prática deva cessar, e penso ser útil analisar essa prática e discutir suas regras de trabalho. 


\section{O éter como elemento explicativo}

Voltemos ao caso do éter. Consideremos um espaço aparentemente vazio. Se não for preciso supor lá algo inobservável para explicar algum fenômeno, então será difícil justificar a defesa do éter. Mas, de acordo com a posição aqui defendida, a introdução do éter será cientificamente útil se ele permitir compreender algo que não pode ser compreendido somente com relação aos entes observáveis. Negar sempre a possibilidade de existência de algo onde nada se observa é impor uma restrição excessiva ao pensamento científico. No entanto, algumas vezes a introdução de inobserváveis pode ser uma complicação desnecessária.

Assim sendo, a discussão sobre se o éter deve ser introduzido ou não depende de uma questão empírica, até certo ponto: é preciso determinar se há fenômenos que não podem ser entendidos se for suposto um vácuo absoluto. E apenas o conhecimento fatual da ciência pode nos dizer isso.

Vamos agora examinar alguns fenômenos que podem ocorrer no vácuo, a fim de verificar se são compreensíveis sem um éter.

Um dos argumentos de Aristóteles contra o vácuo utilizava o fenômeno de queda dos corpos. Ele argumentava que, se não existisse nada que pudesse oferecer resistência à queda de um corpo, esse corpo percorreria uma certa distância finita em um tempo nulo, o que é inconcebível; portanto, não pode haver um vácuo absoluto, ou um espaço sem nenhuma resistência à queda dos corpos. Ora, quando Torricelli e Pascal mostraram a possibilidade de se criar um espaço aparentemente vazio, verificou-se que os corpos não caíam instantaneamente nesse espaço. Como compreender isso? Na época, era impossível compreender isso, pois não existia ainda a mecânica de Newton, que estabeleceu o conceito de inércia e a relação entre força e aceleração. Nesse contexto, para se explicar a velocidade finita de queda dos corpos, a melhor explicação era a da existência de uma resistência; e, portanto, o espaço não estava totalmente vazio. Este é um caso em que o éter ou matéria sutil tinha um claro poder explicativo. Posteriormente, com a mecânica newtoniana, tornou-se desnecessário o uso da idéia de resistência do éter. Mas, antes disso, a idéia era excelente. Ou seja: a necessidade ou não de se introduzir um determinado ente inobservável é contextual e depende do estado de conhecimentos empíricos, assim como da teoria existente na época.

No século XVII, por ocasião dos estudos barométricos, observou-se também que a luz era capaz de atravessar o vazio aparente no alto do barômetro de mercúrio. Surgiu, então, a famosa dúvida: será a luz um corpo (uma substância), ou um acidente (uma afecção de uma substância)? Se ela fosse um corpo, como poderia atravessar outros corpos (o vidro, a água, o diamante) e como um feixe luminoso poderia atravessar outro feixe, sem colidirem? Mas, se ela não for um corpo, sua propagação pelo vazio barométrico não será uma prova de que esse vazio contém algo no qual a luz se propaga? 
É claro que a propagação da luz no vácuo relativo não soluciona nada, enquanto não se sabe o que é a luz; mas ela nos mostra exatamente o tipo de questão que pode ser colocada para se discutir claramente o problema. O fato observável é que a luz é capaz de atravessar o espaço aparentemente vazio. Nenhuma discussão sobre isso. Dado esse fato, se a luz é um acidente, então o espaço aparentemente vazio não é um vácuo absoluto; se a luz é uma substância, então nada se conclui sobre a natureza do espaço aparentemente vazio.

Quando, no século XIX, a teoria ondulatória da luz superou a teoria corpuscular, tornou-se inevitável a volta do éter. Colocando-se o argumento em sua forma mais curta, o éter é, por definição, o sujeito do verbo "ondular", quando a luz é descrita como uma ondulação". Por que motivo o verbo "ondular" precisa de um sujeito especial? Por que não se pode dizer que é a própria luz que ondula? Não é possível apresentar aqui os detalhes do argumento, que envolvem conhecimentos físicos do fenômeno de interferência. Mas, colocando de uma forma simples, pode-se dizer que duas porções de luz podem se destruir mutuamente em um ponto e que duas substâncias não podem se aniquilar. Por isso, a luz não poderia ser uma substância, mas um processo ocorrendo necessariamente em alguma substância (Maxwell, 1965, p. 764).

Da mesma forma, verificou-se que os efeitos elétricos, magnéticos e gravitacionais se manifestavam mesmo no espaço evacuado, assim como ocorre no ar. Como pode isso ocorrer? Há algumas alternativas: ou por ação à distância, ou por intermédio de algo (um meio). Mas não é uma ação à distância incompreensível ${ }^{10}$ ? Não será isso, então, uma indicação de que o vazio aparente contém algo, que transmite as forças eletromagnéticas e gravitacionais?

É interessante observar como a Física do século XX trata essa questão. A ação a distância não é admitida; mas o éter também é rejeitado. Supõe-se que no vácuo podem existir "campos" (elétrico, magnético, gravitacional) capazes de atuar sobre os corpos lá colocados. Mas podemos perguntar: o que são esses campos? São entes (substâncias) ou acidentes de algo? Se eles são entes, então o vácuo onde há um campo não é um vácuo absoluto (um espaço sem nada nele). Se não são entes, então devem ser modificações de algo - e esse algo existe no vácuo aparente, que não é, portanto, um vácuo absoluto. Dependendo da concepção que se tenha sobre a gravitação e o eletromagnetismo, o fato de que essas forças existem mesmo no espaço aparentemente vazio pode levar necessariamente à conclusão de que não se trata de um vácuo absoluto.

A Física pós-Einsteiniana não responde a esse dilema. Para os físicos, usualmente desprovidos de treino filosófico, nem vale a pena discutir essas questões. Sem percebê-lo, costumam admitir uma concepção autocontraditória - a de que os campos não são propriedades ou modificações de uma coisa (não são acidentes), porém não são também substâncias - e, por isso, um espaço sem matéria no qual há um campo seria um vácuo absoluto. 
Para perceber o absurdo dessa concepção, basta fazer algumas comparações: um espaço totalmente vazio pode ser verde? pode ser quente? pode ter uma densidade? Não. Da mesma forma, ele não pode ter uma intensidade de campo elétrico.

Vamos esclarecer melhor certos termos.

Todas as grandezas físicas mensuráveis são propriedades quantitativas. Toda propriedade pertence a algum sujeito. O sujeito de uma propriedade é um ente, uma substância. As propriedades podem ser pensadas abstratamente como algo isolado, mas não se pode pensar que uma propriedade exista, em certo local e tempo, sem um substrato. Uma temperatura é a temperatura de algum ente; uma força é a força que age em um ente. Não se pode imaginar essas grandezas desligadas de toda substância, vagando por aí. Elas não são substâncias, não podem subsistir sem uma substância. Da mesma forma, o campo elétrico, o campo gravitacional e o campo magnético são propriedades mensuráveis e não podem vagar por aí sem um substrato. Não são substâncias: são grandezas, portanto, são propriedades quantitativas de algo. Se não existe o éter, são propriedades de quem?

Um físico provavelmente responderia: "do espaço vazio". Ocorre que, sem perceber, os físicos dão o nome de "vácuo" ou "espaço vazio" a um ente, a uma substância, a algo que existe e que tem propriedades físicas. O "vácuo" dos físicos do século XX pode ter uma maior ou menor intensidade de campo elétrico, em diferentes direções. Aliás, mesmo na ausência de campos, ele possui certas propriedades: por exemplo, a constante dielétrica do "vácuo".

O físico aceita que o "espaço vazio" possa ter propriedades porque a expressão "espaço vazio" não significa, para ele, um espaço vazio. O espaço vazio, no sentido próprio (absoluto), seria um espaço no qual não existem substâncias (entes) físicas. Para o físico moderno, o "espaço vazio" é um espaço no qual não existe matéria sólida, líquida ou gasosa, mas onde há algo capaz de assumir propriedades. O "espaço vazio" dos físicos atuais é muito semelhante ao éter de Fresnel e de Lorentz, mas tem outro nome.

Para tornar isso ainda mais claro, é importante lembrar que "espaço" não se refere a um conceito físico, e sim matemático. Não existem, no mundo físico, planos, retas, esferas. Há, sim, corpos que podem ter propriedades semelhantes (isomórficas) às de planos, retas, esferas - ou que se aproximem disso. Consideremos uma "esfera" de bronze, pintada de verde. Tiremos sua tinta. Permanece algo físico, uma esfera visível e palpável. Apaguemos a luz. Permanece uma esfera palpável, de bronze. Tiremos o bronze. Não sobra uma esfera. Não existe mais a esfera. A esfera, como tal, separada de um substrato material, não faz parte do mundo físico. Do mesmo modo, uma forma, um volume, uma dimensão ou medida, se fazem parte do mundo físico, devem estar associados a um ente físico, como sujeito de que são propriedades. Na ausência de entes físicos (substâncias), não faz sentido falar na existência de um volume, de uma forma ou de uma dimensão. O nada não tem propriedades. 
Pode-se dizer que os físicos atuais não estão conscientes disso, mas de fato aceitam a existência de algo semelhante ao éter. Mas preferem chamá-lo de "vácuo" ou de "espaço vazio", o que torna tudo obscuro e até contraditório.

\section{Concepções úteis ao desenvolvimento científico}

Há ainda um outro ponto de vista que vale a pena indicar. Sob o ponto de vista heurístico e metodológico, e não da realidade (ontologia) ou da utilidade explicativa, há certas concepções que são úteis ao progresso científico e outras que prejudicam ou inibem esse progresso. Por exemplo: o universo pode ser considerado como compreensível ou incompreensível. Não sabemos se ele de fato é compreensível ou não; mas supor que é compreensível estimula a pesquisa e a busca de causas e de leis; supor que não é, desestimula a pesquisa científica. Da mesma forma, poderíamos supor que as leis científicas atualmente aceitas são verdadeiras e finais ou que são falsas e temporárias. Não sabemos qual a verdade. Mas é útil, sob o ponto de vista do progresso científico, supor que as leis atualmente aceitas são falsas ou imperfeitas e procurar outras leis ou exceções às leis conhecidas.

Um exemplo mais restrito: pode-se supor que as chamadas "partículas elementares" são de fato "elementares" (isto é, sem partes, indecomponíveis) ou que é possível descobrir sua constituição. A primeira atitude é conservadora e limita a pesquisa àquilo que já é conhecido. A segunda atitude é capaz de estimular a pesquisa do desconhecido e pode, portanto, levar mais facilmente ao progresso da ciência. Supor que nada existe no universo além do que já conhecemos, é uma crença que desestimula a pesquisa. Uma de suas formas é exatamente a negação do inobservável - e a negação do éter, em particular. Se supomos que existe o éter, abre-se um novo campo de indagações e de pesquisa; se supomos que, ao retirar tudo o que percebemos de um recipiente, lá não resta nada, não há o que investigar nesse local. Assim, como concepção diretriz para a pesquisa, é preferível supor a existência do éter do que negá-lo.

Deve-se deixar claro que este argumento nada adiciona sobre a questão da existência ou não do vácuo ou do éter. Apenas indica que os defensores do vácuo adotam uma posição conservadora e que os defensores do éter adotam uma posição progressista, sob o ponto de vista do futuro da ciência.

\section{A impossibilidade a priori do vácuo absoluto}

Os argumentos apresentados até agora procuraram mostrar que não é possível rejeitar empiricamente a existência de um éter; que essa concepção pode ser 
cientificamente útil para se explicar certos fenômenos físicos, e que ela é útil sob o ponto de vista heurístico. Como a utilidade explicativa depende da situação física específica a ser estudada e do contexto conceitual utilizado, pode parecer que a questão permanece indefinida. Pode-se, no entanto, ir mais longe. É possível mostrar, de um modo ainda mais forte, que a própria concepção do vácuo absoluto é inaceitável e que, portanto, em todo lugar aparentemente vazio, é necessário supor a existência de um ente físico. Se esse ente físico é denominado éter ou não, isso é uma questão de nomenclatura e, portanto, arbitrária; mas qualquer que seja o nome, esse ente preencherá exatamente o mesmo papel que o antigo éter.

Suponhamos que seja possível imaginar um vácuo absoluto, no nosso universo físico. Suponhamos que ele ocupe um certo volume, em uma certa região do espaço. Esse vácuo deverá ter uma forma determinada, e um volume $V$ definido, que não seja nulo (se o volume for nulo, isso indica simplesmente que o espaço não existe). Consideremos, agora, um corpo físico sólido, com mesma forma e tamanho que esse espaço vazio. Seu volume será, evidentemente, igual ao volume V do espaço vazio considerado. Agora, suponhamos que o corpo seja transladado até ocupar exatamente o espaço que antes estava vazio. Qual será o volume existente, agora, nesse espaço? Se o espaço vazio tinha volume $V$ e o corpo tem volume $V$, o espaço preenchido pode ter ou volume $2 \mathrm{~V}$ ou volume $\mathrm{V}$. Se ele tiver um volume $2 \mathrm{~V}$, teremos um absurdo: $u$ volume $\mathrm{V}$ pode conter um volume $2 \mathrm{~V}$. Se ele só contiver um volume $\mathrm{V}$, teremos um problema: como foi que sumiu o volume do espaço vazio ou do corpo?

A solução do problema é muito simples: basta negar a possibilidade de um espaço vazio com certo volume. Pois, se a hipótese inicial é aceita, não parece possível escapar a conclusões paradoxais.

Esse argumento não é novo: é um argumento medieval, baseado em Aristóteles ${ }^{11}$. Apesar de antigo, é perfeitamente rigoroso e atual. Ele não se reduz a um jogo de palavras, como pode parecer à primeira vista. Ele trabalha, na verdade, com um jogo de conceitos contraditórios associados à idéia do vácuo absoluto. O vácuo absoluto é, por definição, a ausência de toda substância; o volume é um atributo que pertence, necessariamente, a algum sujeito, ou seja, a uma substância (no sentido aristotélico). Portanto, não se pode pensar em um volume sem substância e, ao se atribuir um volume ao vácuo absoluto, temos dois conceitos contraditórios, dos quais surgem muitos paradoxos. Não se pode pensar coerentemente em um vazio absoluto que tenha dimensões, pois as dimensões (distância etc.) são necessariamente atributos de um ente e o não-ente (o vácuo absoluto) não pode ter atributos.

Esse raciocínio pode ser colocado de uma forma ainda mais extrema, mas ainda correta: um nada não pode ser maior do que outro nada. Por isso, não podem existir vácuos diferentes. Portanto, não se pode pensar em espaços vazios (no sentido absoluto) com diferentes volumes, formas etc.

Alguém poderia objetar: "Mas eu consigo imaginar um espaço totalmente vazio com certa forma e volume". Isso é impossível. Pode-se, sim, imaginar um espaço de certa forma e volume que seja de natureza não definida ou que seja diferente daquilo 
que o cerca. Pode-se imaginar que ele não tem massa, que não tem cor etc. Mas não se pode privá-lo, mesmo em imaginação, de sua substancialidade, pois se ele possui forma e volume possui atributos e é, necessariamente, uma substância.

Pode-se talvez julgar que, nesse caso, a designação "substância" é pouco significativa e que falar em um vácuo absoluto ou em um espaço vazio que só possua volume e forma é a mesma coisa. Não é a mesma coisa. Pois o espaço matemático em si não é um ente físico e um espaço físico, com forma e volume, que seja, portanto, uma substância, é muito diferente do vácuo absoluto. Pois, se ele é um "algo" físico, apenas a experiência pode dizer quais são as suas propriedades físicas e indicar quais outros atributos, além de volume e forma, ele possui ou não possui. Pelo contrário, um vácuo absoluto não pode possuir nenhuma propriedade física e, portanto, não é sujeito de pesquisa empírica de suas propriedades.

\section{Os argumentos filosóficos contra o vácuo, na História}

Os argumentos acima apresentados não são novos, como já foi dito. Sem querer fazer aqui a história desses argumentos, é útil indicar pelo menos alguns exemplos ilustrativos.

Vamos rever o clássico argumento de Descartes em que ele procura estabelecer a priori a impossibilidade do vácuo. Primeiramente, ele argumenta que a natureza essencial de um corpo é a sua extensão, já que podemos imaginá-lo privado de qualquer outro atributo além da extensão sem que ele perca sua corporalidade.

11. Em que sentido se pode dizer que ele [o espaço ou lugar interior de um corpo] não é diferente do corpo que ele contém.

Mas será fácil conhecer que a própria extensão que constitui a natureza do corpo constitui também a natureza do espaço, de modo que eles apenas diferem entre si como a natureza do gênero ou da espécie difere da natureza do indivíduo, se, para melhor discernir qual é a verdadeira idéia que temos do corpo, tomarmos por exemplo uma pedra e lhe retirarmos tudo aquilo que sabemos não pertencer à natureza do corpo. Retiremos portanto primeiramente sua dureza, pois, se reduzíssemos essa pedra em pó, ela não teria mais dureza, e não deixaria por isso de ser um corpo; retiremos dela também a cor, pois já podemos ter visto algumas vezes pedras tão transparentes que elas não tinham cor; retiremos dela o peso, pois vemos que o fogo, embora seja muito leve, não deixa de ser um corpo; retiremos dela o frio, o calor e todas as outras qualidades desse gênero, pois não pensamos que estejam na pedra, ou que essa pedra mude de natureza porque nos parece às vezes quente, às vezes fria. Depois de ter assim examinado essa pedra, encontraremos que a verdadeira idéia que dela temos consiste apenas nisso: que percebemos distintamente que ela é uma substância extensa em comprimento, largura e profundidade: ora, o mesmo está compreendido na idéia que temos do espaço, não apenas daquele que está preenchido por um corpo, mas também daquele que se chama vazio. (Descartes. 1964-72, p.68-9) 
Não só a extensão é essencial à concepção de corpo, mas, inversamente, a concepção de corpo está ligada indissoluvelmente à extensão: é impossível pensar em um corpo sem extensão e vice-versa. Sem esse "vice-versa", não é possível negar o vácuo. O argumento de Descartes prossegue:

\section{Que não pode existir nenhum vazio no sentido em que os Filósofos tomam esta palavra.}

Quanto ao vazio, no sentido em que os Filósofos tomam esta palavra, ou seja, por um espaço no qual não exista substância, é evidente que não existe nenhum espaço no universo que assim seja, pois a extensão do espaço ou do local interno não é diferente da extensão do corpo. E como apenas por um corpo ser extenso em comprimento, largura e profundidade podemos concluir que ele é uma substância, pois não concebemos que seja possível que aquilo que nada é tenha extensão, devemos concluir o mesmo do espaço que se supõe vazio: ou seja, que, já que existe nele extensão, existe também necessariamente substância. (Descartes, 1964-72, p. 71-2)

Ou seja: Descartes estabelece a impossibilidade do vácuo por ser impossível pensar em um atributo (a extensão) sem um sujeito (uma substância). "Aquilo que não é não pode ter extensão".

Podemos encontrar em Avicenne, por exemplo, um argumento do mesmo tipo:

Diremos: se o vácuo existe, ele não é como seus defensores o imaginam, dizendo que o vácuo é o não-ser. De fato, como se poderia dizer que ele é o não-ser, se é possível dizer que entre tal ou tal corpo há mais vazio do que entre tal e tal outro? E como se poderia dizer que uma certa quantidade de substância cabe em certa quantidade de vácuo, e que mais do que essa quantidade não caberia, e que menos do que essa quantidade criaria uma privação? Ora, tu já sabes que isso não se aplica ao não-ser. Portanto, se o vácuo existisse, ele seria uma coisa dotada de grandeza, ele seria susbstância e não acidente, pois ele subsiste em si próprio e porque ele não pertence a um sujeito. Tu já sabes que a grandeza não é, ela própria, substância. Portanto, o vácuo não é a própria grandeza; portanto ele é uma substância com grandeza. Ora, tudo o que é assim é o pleno e é um corpo; logo o vácuo é um corpo. (Avicenne, 1958, p. 23-4)

Em seguida, Descartes discute um velho problema escolástico: o que ocorreria se Deus retirasse tudo do interior de um recipiente? Não surgiria aí um espaço vazio, no sentido absoluto?

\section{Como se pode corrigir a falsa opinião preconcebida sobre o vácuo}

Quase todos nós fomos previamente ocupados por este erro desde o início de nossa vida, pois, vendo que não existe uma ligação necessária entre o vaso e o corpo que ele contém, pareceu-nos que Deus poderia tirar todo corpo que está contido em um vaso e conservar esse vaso em seu mesmo estado, sem que houvesse necessidade de que algum outro corpo tomasse o lugar daquele que se tivesse tirado. Mas, para que possamos agora corrigir uma opinião tão falsa, notaremos que não existe ligação necessária entre o vaso e um tal corpo que o preenche, mas que ela é tão necessária entre a figura côncava que esse vaso possui e a extensão que deve estar compreendida nessa concavidade, que não é menos repugnante conceber uma montanha sem vale do que tal concavidade sem a extensão que ela contém, e essa extensão sem alguma coisa extensa, pois o nada, como já foi observado várias vezes, não pode ter extensão. É por isso que, se nos perguntarem o que ocorreria, no caso em que Deus retirasse todo corpo que está em um vaso, sem permitir que 
lá entrasse outro, responderemos que os lados desse vaso se encontrariam tão próximos que se tocariam diretamente. Pois é necessário que dois corpos se toquem, quando não há nada entre eles, pois existiria contradição em que esses dois corpos estivessem afastados, ou seja, que houvesse distância de um ao outro, e que no entanto essa distância não fosse nada: pois a distância é uma propriedade da extensão, que não poderia subsistir sem alguma coisa extensa. (Descartes, 1964-72, p. 72-3)

Pode parecer que Descartes está utilizando apenas um jogo de palavras: se tirarmos tudo de dentro de um recipiente, dentro dele nada existe; e se nada existe entre suas paredes, essas paredes se tocam. Isso seria um jogo de palavras, se o termo "nada" fosse utilizado em dois significados diferentes, criando assim um sofisma. Pode-se tentar argumentar contra Descartes que o "tudo" que foi retirado se refere às substâncias lá contidas e que, portanto, o primeiro "nada" representa a ausência de substâncias; mas, para concluir que as paredes se tocam, é necessário supor que não há uma distância entre elas, e pode-se supor um "nada" de substância sem se supor um "nada" de distância. Ou seja: os dois "nadas" podem ser considerados diferentes, se for possível distinguir a extensão da substância. Mas isso é justamente o que Descartes indica ser impossível. Uma extensão sem substância é impensável, pois é um atributo sem sujeito.

Descartes não foi, evidentemente, o primeiro a apresentar esse tipo de argumento.

Alberto da Saxônia, no século XIV, apresenta o seguinte argumento contra o vácuo:

\begin{abstract}
"Vácuo" deve ser cogitado de dois modos: em um modo, como um espaço separado no qual não existe qualquer outro corpo conjuntamente...

É impossivel que um vácuo exista, falando sobre o vácuo do primeiro modo. Isso pode ser provado porque no primeiro modo um vácuo é uma dimensão separada e isso não pode ser assumido, pois não se pode assumir a existência de um acidente separado sem um sujeito. Em segundo lugar, se tal espaço separado fosse assumido, seguir-se-ia que, sendo ele um corpo (pois teria comprimento, largura e profundidade) ocorreria uma interpenetração de corpos quando ele recebesse algo que fosse colocado nele, o que é impossível... (Grant, 1974, p. 324-5)
\end{abstract}

O argumento da interpenetração é colocado de modo muito claro em vários autores, como, por exemplo, Avicenne. Ele começa explicando porque não se pode conceber a penetração mútua de dois corpos.

A impossibilidade de que um corpo penetre em outro não é por causa de serem eles quentes ou frios, ou negros ou brancos, ou que eles possuam cada um dos nove atributos, ou por serem compatíveis ou incompatíveis; senão, seria necessário que todos aqueles que não possuem esses atributos penetrassem uns nos outros.

... A causa é portanto que uma grandeza não pode penetrar em outra; e isso porque duas grandezas juntas formam mais do que uma grandeza sozinha. Não pode ocorrer que duas grandezas se unam, cada uma delas continuando a existir, e as duas tornando-se iguais a uma só. (Avicenne, 1958, p. 22-3) 
A partir daí, Avicenne vai indicar como conseqüência que também não se pode conceber um espaço vazio extenso no qual pudesse penetrar um corpo também extenso, pois isso é tão impensável quanto a penetração mútua de dois corpos. Um argumento semelhante se encontra ainda antes, em Sextus Empiricus:

Eis um outro argumento. Como não se vê em dobro as dimensões em cada uma das coisas que estão em um lugar, mas um comprimento, uma largura, uma profundidade, essas dimensões pertencem apenas ao corpo, ou apenas ao lugar, ou aos dois? Se elas pertencem apenas ao lugar, o corpo não teria comprimento, largura e profundidades próprias e o corpo não será mais um corpo, o que é absurdo. Se elas pertencem aos dois, como o vácuo não existe senão por suas dimensões, se as dimensões do vácuo são as do próprio corpo e o constituem, aquilo que constitui o vácuo constitui também o corpo... Se as dimensões pertencem apenas ao corpo, o lugar não terá nenhuma dimensão e portanto não existirá o lugar. (Sextus Empiricus, 1948, p. 307)

É interessante notar como, ao tentar conceber uma noção de "espaço puro", alguns pensadores chegaram a conflitos e tiveram que fazer afirmações paradoxais. No século XVI, Francesco Patrizi tenta descrever um espaço vazio que precedesse a criação do universo, e é levado à seguinte concepção:

O que, finalmente, é este espaço...? Se ele é algo, ele será ou uma substância ou um acidente. Se for uma substância, será ou um corpo ou uma coisa incorpórea. Se ele for um acidente, será ou uma quantidade, ou uma qualidade, ou alguma outra coisa parecida.

... O espaço é portanto uma extensão substancial (extensio hypostatica), subsistindo em si, sem estar inerente em outro. Não é uma quantidade - ou, se for uma quantidade, não é a das categorias, mas anterior a elas e sua fonte e origem. Não pode ser chamado de acidente, pois não é o atributo de nenhuma substância.

É ele então uma substância? Se a substância é id quod per se substat, o espaço é acima de tudo uma substância, pois ele subsiste por si e não depende de mais nada para ser, ele não exige nada para sustentá-lo, mas proporciona sustento a todas as substâncias e as sustenta em seu ser. Se substância é quodper se existit, o espaço é acima de tudo uma substância, pois acima de tudo ele existe por si. Se substância é quae aliis substat, o espaço é acima de tudo substância, pois sustenta todas as outras coisas na natureza. Se substância é quae nulla aliarum rerum eget ad esse, então o espaço é acima de tudo uma substância, pois não exige nada mais para sua existência, enquanto todas as outras coisas necessitam do espaço para sua existência. Se substância é primum omnium entium, o espaço éacima de tudo uma substância, pois já se mostrou que ele é anterior a todas as outras coisas.

Por todas essas razões, portanto, é muito claro que o espaço é acima de tudo uma substância; mas não a "substância" da categoria. Pois não é uma substância individual, já que não é composto por matéria e forma. Nem é um gênero, pois não é predicado de espécies nem de coisas individuais. É, portanto, um tipo de substância diferente, fora da tabela das categorias. O que é ele então, um corpo ou uma substância incorpórea? Nenhum dos dois, mas intermediário entre eles. Não é um corpo, pois não mostra resistência, nem é jamais objeto de visão, tato ou qualquer outro sentido. Por outro lado, não é incorpóreo, pois é tridimensional. Tem comprimento, largura e profundidade - não apenas uma, duas ou algumas dessas dimensões, mas todas elas. Portanto é um corpo incorpóreo e um não-corpo corpóreo. (Patrizi, 1943, p. 240-1)

Qualquer pensador atual que tente descrever o espaço vazio dos físicos contemporâneos teria que chegar igualmente a esse tipo de descrição paradoxal. Não há 
alternativas além dessas: ou se admite a impossibilidade de se pensar sobre o vácuo absoluto ou espaço vazio; ou se conceitua esse vácuo como um "corpo incorpóreo e um não-corpo corpóreo".

Por fim, é importante deixar claro que as indicações históricas aqui apresentadas são apenas ilustrações que indicam, por um lado, que certos argumentos são muito antigos, e que não pretendo estar sendo original, de forma nenhuma, ao argumentar contra o vácuo. No entanto, as citações não possuem o papel de argumentos de autoridade. Não é porque Kant ou Descartes ou qualquer outro autor apresentou um argumento, que ele se torna válido (ou inválido). Foi para deixar claro que defendo os argumentos em si próprios como válidos e que não tento justificá-los por argumento de autoridade, que separei em seções distintas a sua apresentação geral e a ilustração histórica.

\section{Conclusão}

Há até hoje uma visão ingênua do papel da experimentação na ciência, que ridiculariza o uso de raciocínios a priori. Um exemplo dessa visão é o famoso episódio introduzido por Brecht na sua peça teatral Galileo Galilei, em que os filósofos escolásticos se recusam a olhar pelo telescópio de Galileo sem antes discutir a possibilidade teórica de ver aquilo que Galileo diz que pode ser visto através do instrumento. "Recusar-se a olhar pelo telescópio de Galileo" tornou-se uma representação simbólica de um espírito anticientífico e preconceituoso.

Suponhamos que alguém, hoje, dissesse: "Venha, já que você não acredita, eu vou lhe mostrar um vácuo". Qual seria a atitude "científica", nesse caso? Em minha opinião, a melhor atitude é algo muito parecido com a atitude atribuída por Brecht aos filósofos peripatéticos: "Não vou perder tempo tentando ver algo que não pode ser mostrado". A razão pode provar que não se pode mostrar um vácuo. E isso independe do progresso científico, dos aparelhos porventura inventados etc.

A razão não é onipotente; mas o empirismo também não o é. Nosso conhecimento científico é uma combinação de elementos vindos da experiência com elementos vindos da razão. Quando um desses instrumentos tenta invadir o campo do outro, nada de bom pode resultar.

Este artigo procurou mostrar que uma concepção hoje em descrédito na ciência - a de um éter - é preferível à concepção de um vácuo, por vários motivos. Em primeiro lugar, porque não se pode mostrar, empiricamente, que o éter não existe; em segundo lugar, porque um vácuo é impensável; em terceiro, porque a concepção de um éter é útil à compreensão dos fenômenos físicos; e, em quarto lugar, porque a hipótese da existência de um éter em espaços aparentemente vazios é útil ao progresso futuro da ciência. O artigo procurou mostrar também que nenhum avanço recente da ciência alterou essas antigas conclusões e que nenhum avanço futuro pode alterá-las. 


\section{Agradecimento}

Esta pesquisa foiapoiada pelo Conselho Nacional de Desenvolvimento Científico e Tecnológico (CNPq).

\section{Notas}

2. As concepções sobre o éter sempre variam de autor para autor e por isso é um abuso de linguagem falar sobre "o" éter. No entanto, como a discussão aqui desenvolvida não depende de forma crucial das diferenças entre essas concepções e sim daquilo que elas possuem em comum, é possível adotar essa simplificação. Sobre as metamorfoses da concepção do éter no século XIX, ver o artigo de Nercessian (1984).

3. Na verdade, não é necessário negar a teoria da relatividade para afirmar a existência de um éter. Em um certo sentido, Einstein voltou à idéia de um éter na teoria da relatividade geral. Ver, por exemplo, o artigo de Mackaye (1932). No entanto, a versão mais aceita da teoria da relatividade é acompanhada pela negação do éter.

4. Martin Gardner já realizou um estudo (1957), hoje clássico, sobre os excêntricos (cranks) que teimam em defender idéias claramente erradas ou sem base científica.

5. Isso, é verdade, é um exagero: mesmo o melhor vácuo que se possa produzir em laboratório ainda contém vapores e gases rarefeitos; mas vamos admitir, por simplicidade, que se possa reduzir tanto esses gases e vapores que eles não possam mais ser detectados.

6. É evidente que toda essa discussão tem um sentido diferente dentro da visão de Kant, em que o espaço não é uma "coisa em si" mas apenas uma forma necessária de nossa intuição. No entanto, o aspecto aqui colocado por Kant deve ser admitido até mesmo em uma concepção realista da ciência.

7. Ao classificar este ou outro argumento como positivista, não se está julgando o argumento. Recusar a priori um argumento, sem analisá-lo, apenas porque "é um argumento positivista" é uma atitude preconceituosa, incompatível com a atitude que se espera de um filósofo.

8. Uma discussão "clássica" sobre inobserváveis é apresentada por Dingle (1938). A análise deste artigo não segue, no entanto, a classificação de Dingle. Para uma descrição geral do operacionalismo e da bibliografia sobre esse assunto, ver Martins (1982).

9. Este argumento é apresentado por Campbell (1910), que o atribui a Lord Salisbury, sem indicar a fonte.

10. A idéia de ação a distância é extremamente problemática. Dois corpos distantes, A e B, se atraem; a direção e a intensidade da força dependem das características dos corpos (suas massas, cargas elétricas e formas) e de suas posições. A força "sentida" pelo corpo A depende de onde está e do que é o corpo B. Mas o corpo A não tem olhos. Como ele poderia "saber" o que é e onde está o corpo B? De alguma forma, as informações sobre 
a massa ou carga de B, sua direção e distância são comunicadas a A. Mas como? Por telepatia?

Desde a Antigüidade, confrontados com a existência do magnetismo e da atração elétrica, os atomistas haviam tentado resolver esse problema introduzindo intermediários: partículas que seriam emitidas pelo ímã, que fossem até o ferro e, de alguma forma, lhe transmitissem a atração. Não era necessário supor que o espaço estivesse cheio com alguma coisa; mas parecia incompreensível que uma força atuasse à distância, sem nenhum suporte material.

11. Este argumento é uma adaptação do apresentado por Aristóteles na sua Physica, 216a 26-216b 20.

MARTINS, R. de $A$. In search for nothing: remarks on the arguments for and against the vacuum. Trans/Form/Ação; São Paulo, v. 16, p. 7-27, 1993.

- ABSTRACT: This paper discusses the possibility of an absolute vacuum - a space without any substance. The motivation of this study is the contrast between most philosophers, up to Descartes, who stated that a vacuum was impossible, and the 17th century change of outlook, when the possibility and effective existence of the vacuum was accepted after the experiments of Torricelli and Pascal. This article attempts to show that, contrary to the received opinion, the acceptance of an ether is preferable to the acceptance of a vacuum for several reasons. First: it is impossible to provide an empirical proof of the non-existence of the ether; second, an absolute vacuum is unthinkable; third, the ether concept is useful for the understanding of physical phaenomena; and fourth, the hypothesis of an ether in apparently void spaces is useful for the future development of science. The paper also endeavours to show that no recent advance of science has changed those conclusions and that no future development can change them.

- KEYWORDS: Space; vacuum; ether; a priori knowledge; observables; epistemology.

\section{Referências bibliográficas}

AVICENNE. Le livre de science (Dânesh-nâme). Trad. Mohammad Achena e Henri Massé. Paris: Belles Lettres, 1958. 2 v.

CAMPBELL, N. The aether. Philosophical Magazine. Basingstoke, v. 4, n. 19, p. 181-91, 1910. DESCARTES, R. Principes de la philosophie. In: ADAM, C. \& TANNERY, P. (Ed.). Oeuvres de Descartes. Paris: J. Vrin, 1964-72. v. IX-2.

DINGLE, H. Science and the unobservable. Nature, London, v. 141, p. 21-8, 1938.

GARDNER, M. Fads and fallacies, in the name of science. New York: Dover, 1957.

GRANT, E. A source book in medieval science. Cambridge, MA: Harvard University, 1974. HEISEMBERG, W. The physical principles of the quantum theory. New York: Dover, 1956. KANT, I. Premiers principes métaphysiques dela nature. Trad. J. Gibelin. Paris: J. Vrin, 1971. 
MACKAYE, J. Evidence for the existence of the ether. Journal of the Franklin Institute, Elmsford, New York, v. 213, p. 421-38, 1932.

MARTINS, R. de A. Use and violation of operationalism in relativity. Manuscrito, Campinas, v. 5 , n. 2, p. 103-15, 1981.

A visão operacional dos conceitos e medidas físicas. Revistas de Ensino de Física, São Paulo, v. 5, p. 57-84, 1982.

. O vácuo e a pressão atmosférica, da Antigüidade a Pascal. Cadernos de História e Filosofia da Ciência, Campinas, v. 2, n. 1, no especial, p. 9-48, 1989.

MAXWELL, J. C. Ether. In: NIVEN, W. D. (Ed.). The scientific papers of James Clerk Maxwell. New York: Dover, 1965, v. 2, p. 763-775.

NERCESSIAN, N. J. Aether or: the creation of scientific concepts. Studies in History and Philosophy of Science, Elmsford, New York, v. 15, p. 175-212, 1984.

PATRIZI, F. On physical space. Trad. Benjamin Brickman. Journal of the History of Ideas, Philadelphia, v. 4, p. 224-45, 1943.

SEXTUS EMPIRICUS. Oeuvres choisies. Trad. Jean Grenier e Genevieve Gordon. Paris: Montaigne, 1948. 